\title{
Commuting to the future: Assessing the relationship between individuals' usage of information and communications technology, personal attitudes, characteristics and mode choice
}

\author{
Dea van Lierop ${ }^{1}$ (1) - Francisco J. Bahamonde-Birke ${ }^{1}$
}

Accepted: 5 April 2021/Published online: 23 June 2021

(C) The Author(s) 2021

\begin{abstract}
Innovations in transportation and communications technologies influence the development of cities and how people move through them. Since the widespread adoption of smartphones, mobility and information and communication technology (ICT) have become increasingly interconnected, and there may be a possibility for mobile technologies to nudge, or influence, individuals to travel using sustainable, and collective modes. It remains unclear whether social, financial, or ICT incentives would be effective to nudge the use of sustainable modes. The objective of the study is to understand the reasons affecting modal choices and how the use of ICTs and personal opinions and attitudes influence the decision-making process. A discrete choice model is used to consider five transportation alternatives including three single modes, namely bicycle, transit, and car, and two multimodal possibilities, bicycle and transit as well as park and ride (car and transit). The target population for this study are Utrecht University employees, who travel to a large university campus located in Utrecht, the Netherlands. The results of the person-based mode-choice model demonstrate that strong correlations exist between the kinds of mobile applications individuals use, their attitudes towards travel, their personal characteristics and their transportation mode. No mobile application seems to favor the use of active modes, which cast doubts upon the use of ICT to promote sustainable transportation. However, social incentives may play an important role for certain groups as individuals who are influenced by their friends, family, and colleagues, are less likely to travel by car or to use park \& ride facilities.
\end{abstract}

Keywords Mode choice - Information and communications technology · Attitudes · Sustainable travel

Dea van Lierop

d.s.vanlierop@uu.nl

Extended author information available on the last page of the article 


\section{Introduction}

\subsection{Adopting Sustainable Modes}

Innovations in transportation and communications technologies influence the development of cities and how people move through them. The transportation choices that people make can have an impact on the overall sustainability of cities as well as on individuals' health (Sallis et al. 2004; Jacobson et al. 2011; Wasfi et al. 2013), and policy makers have developed significant efforts to promote the use of sustainable modes such as walking, cycling, and transit (Cervero et al. 2002; Ogilvie et al. 2004). City planners, policy makers, and transportation professionals now face the important challenge of developing effective strategies to nudge individuals to travel using sustainable modes. Regional employment hubs including both privately and publicly planned and operated regions are beginning to develop incentive schemes to promote sustainable commuting. While planning for sustainable travel often encompasses the promotion of multi-modal integration including the use of bicycles, rail, bus, and shared-cars, policy makers often face challenges in implementing systems that result in individuals' adopting more environmentally and socially sustainable travel habits. Yet, since the widespread adoption of smartphones in the early 2010s, mobility and information and communication technology (ICT) have become increasingly interconnected, and in some cases mobile technologies are being used to promote sustainable travel (Sunio and Schmöcker 2017).

Today, car-share, ride-share, and bike-share systems already rely heavily on communications technology, usually in the form of mobile applications, to connect users (and potential users) to their preferred modes of transportation. For the users of public transit systems, real-time information related to vehicle location and crowding also provide information about the status of the transport services they interact with. In the future it is expected that the relationship between mode choice and ICT will only become stronger as mobility service schemes that depend on mobile payments and offer on-demand personal mobility become more normative. Innovations in transportation and communications technology are thus uniquely interrelated and bound to one another through the users of these services and modes of transportation. In other words, when it comes to mode choice, it is the individual users who connect the pieces of the ICT and transportation puzzle.

However, nudging policies related to ICTs and mobile applications may not be equally effective for motivating the adoption of sustainable travel modes among all commuters. To better understand how individuals adopt and adjust to sustainable and/ or multi-modal travel systems, it is important to understand what motivates individuals to use particular modes. Particularly, as regions, governments, employment hubs, and individual employers develop strategies to promote sustainable travel it becomes necessary to better understand the kinds of strategies that will more likely effect particular mode users. For example, nudging through the use of mobile phone applications will only be useful if these applications are used by the desired population. On the other hand, social incentives related to human relationships and encouragement maybe be more or less useful for particular segments of the population. Accordingly, the current research assesses the relationship between individuals' travel preferences, use of mobile mobility technologies, habits, opinions, personal characteristics, and 
travel choices. The objective of the study is to carefully assess the use of ICTs related to personal mobility and identify how distinct groups of people, or population segments who work at the same employment center, approach modal choice. A discrete choice model is used to consider five transportation alternatives including three single modes, namely bicycle, transit, and car, and two multimodal possibilities, bicycle and transit as well as park and ride (car and transit).

The target population for this study are Utrecht University (UU) employees, who travel to the UU Science Park campus located outside of the city center, on the outskirts of the city of Utrecht, the Netherlands. The population travelling to this location is of interest because the UU Science Park is developing into an employment and mobility hub, which is attracting firms to relocate to this area and thereby increasing commuting in and out of the area. Policies are needed to nudge, or influence, individuals to travel using sustainable, and collective or shared modes. Yet, it remains unclear how to influence particular mode users, and whether social, financial, or ICT incentives would be more effective for particular populations. While financial motivations in transport have been previously studied (Martin et al. 2012), social and ICT motivations in mode choice are not frequently considered. Accordingly, to better understand mode choice, in this study we consider an individual's use of mobile applications, the extent to which an individual reports being influenced by others in their community, as well as other personal and attitudinal variables.

The following section of this study presents a brief review of the relevant literature on the relationship between travel experience, values, motivations, mode choice, and ICTs. Next, the context, data and methodological approach are presented. Finally, the study results are presented and discussed.

\subsection{Travel Experience, Values, Motivations, Mode Choice and Information and Communication Technology}

Mode choice has often been found to be significantly associated with individuals' perceptions regarding travel cost, distance, and time (Button 2010; Turcotte 2011). However, researchers have become increasingly interested in understanding how personal or societal motivations and values may play an important role in mode choice (Bohte et al. 2009). Recent work has shown that issues relating to motivations and values affect levels of travel satisfaction and influence mode choice decisionmaking processes (Gountas and Gountas 2007; Lai and Chen 2011; St-Louis et al. 2014; Şimşekoğlu et al. 2015). The majority of these studies concentrate primarily on understanding travel satisfaction and often account for variables such as age, gender, and employment status. Often, however, limited or no consideration for personal motivations or values is presented in these analyses (van Lierop et al. 2018). Few researchers have begun to accept that non-mode specific factors are often related to how individuals experience travel, suggesting that personal motivations, values, and preference are important considerations for understanding mode choice, and that therefore these underlying personal motivations may also play an important role in the economic and social well-being of cities (Olsson et al. 2013; StLouis et al. 2014). In additional, attention has been given to improving how individuals' attitudes and characteristics can be included in mode choice analyses, 
and findings reveal that attitudes and perceptions are likely to affect choice making processes (Bahamonde-Birke et al. 2017).

Individuals' travel attitudes, perceptions, and personal characteristics have also been used to better understand how different groups of people, or population segments, make choices about travel (Molander et al. 2012; van Lierop and ElGeneidy 2016). Specifically, mobility companies including transport agencies and bike-share companies have begun to show an increasing interest in understanding how different groups of customers' attitudes and perceptions are related to travel satisfaction, loyalty, and mode choice (Transportation Research Board 1998; Chou et al. 2014; van Lierop et al. 2018).

The availability of new communication technology also influences personal travel. For example, ride hailing and car sharing companies often rely on mobile technologies for booking, and the quality of these apps influences loyalty (Nguyen-Phuoc et al. 2020). Both docked and dockless bicycle-sharing programs and other forms of shared micromobility also rely on (potential) users to interact with mobile applications to connect them with shared vehicles (Shaheen et al. 2020). Route planning mobile applications have also increased with popularity since the early 2010s when smart phones became more widely available in many regions, and GPS data from mobile phones has been used to determine mode use (Reddy et al. 2010). Sevtsuk and Ratti (2010) also used the aggregate data of mobile networks to assess urban daily mobility patterns.

While it is clear that mobile phones and travel applications can be used to assess travel patterns and behavior, only limited evidence exists regarding how different segments of the population interact with mobile travel applications before and during travel. For example, a recent study on wayfinding suggested that compared to older cyclists, younger individuals relied significantly more on the Google maps mobile application and less on physical signage for route information (van Lierop et al. 2020).

The present study considers how an individual's mode choice is affected by his or her attitudes, perceptions, personal characteristics and use of ICTs. Latent factor analysis and structural equation modeling are used to identify groups with similar attitudinal traits towards travel, and a discrete choice model is used to assess how these personal traits are related to an individuals' mode choice. The methodology section below provides the details of the analysis.

\section{Data}

\subsection{Context}

The study targets faculty and staff of Utrecht University who commute to Utrecht Science Park, a large university campus located in the east of the City of Utrecht in the Netherlands. The population of the City of Utrecht was 352,866 in 2019, which represents a nearly $50 \%$ growth in the population over the last 20 years (AlleCijfers.nl 2019). The campus is located away from the dense urban city center and is easily accessible by car, public transit, and bicycle. As mentioned previously, the target population does not represent the Utrecht population, but is used to better 
understand how to promote sustainable travel to and from a growing employment hub. Specifically, it assesses the relationship between individuals' mode choice, their attitudes towards travel, personal characteristics and mobile app usage related to travel.

The data used in this research is obtained from an online commuter survey targeting all Utrecht University staff and faculty by including a link to participate in the online survey on the employee internal digital network. Prizes were offered to participants as incentives to take part in the survey. The survey was active for 27 days in April and May 2019. Since survey participants were not sent an invitation email, it is not possible to calculate an accurate response rate. However, 443 full responses were collected from the 5100 employees whose offices are located at the Utrecht University Science Park. Since questions were not mandatory to answer, it was possible for respondents to leave questions blank. Accordingly, for the purposes of this analysis 299 valid responses are used.

\subsection{Survey Design}

The survey was designed to collect information about respondents' commutes to the university campus on a typical good weather day as well as a typical bad weather day. Respondents were asked to describe their commutes by specifying the mode used and the number of minutes using the mode. Respondents were also asked to rate their satisfaction with various trip attributes, as well how they used technology (mobile apps) during various phases of their trip. The survey asked participants about the kinds of travel-related mobile applications they used on a daily basis, and whether applications were used for route planning, scheduling, or mode selection. Additionally, the survey was designed to gather information about respondents' thoughts and opinions on various aspects of travel as well as their socio-demographic information. Table 1 presents the summary statistics and modal composition of the sample, and reveals the percentage of faculty and staff who already use multiple modes to travel to work on a regular day. Nearly half of the sample uses a bicycle to commute to work, and nearly one in five commutes by private car. A quarter of the sample uses transit in combination with bicycle or a private car during their commute to work, and $8 \%$ use only transit. While this mode share may not be common internationally, it is representative of the City of Utrecht where in $201847 \%$ of trips were made by bicycle and $18 \%$ by car (Stumpel and van Weperen 2019). Walking was not reported as a primary mode, as the location of and access to the employment hub makes this an unlikely choice. Accordingly, less than $1 \%$ of the sample reported walking to work without the use of other modes, and these responses were not taken into consideration in this analysis. The mode categories presented in Table 1 are used throughout this analysis. Finally, when asked about the role that mobile applications play in their travel planning, $10 \%$ reported using it for mode selection, $27 \%$ to select the best travel time and $26 \%$ used apps to select the best route. The most popular travel apps used were the local NS train app (16\%), Google maps (16\%) and the local transit app 9292 (14\%).

In addition to mode use, individuals were categorized by their reported use of travel applications. Half of the sample made use of travel applications related to mapping/directions, transit schedules and routes, road congestion, and weather. Forty percent used mobile travel applications before or during their commute to 
Table 1 Summary Statistics

\begin{tabular}{|c|c|c|}
\hline Age & Average: 42 & $\begin{array}{l}\text { Min: } 21 / \\
\text { Max: } 66\end{array}$ \\
\hline \multirow[t]{2}{*}{ Gender } & Male: & $114(38 \%)$ \\
\hline & Female: & $185(62 \%)$ \\
\hline \multirow[t]{5}{*}{ Number of people in household } & 1 person & $69(23 \%)$ \\
\hline & 2 people & $110(37 \%)$ \\
\hline & 3 people & $34(11 \%)$ \\
\hline & 4 people & $72(24 \%)$ \\
\hline & 5 people or more & $14(4 \%)$ \\
\hline \multirow[t]{4}{*}{ Number of children in the household } & No children & $209(70 \%)$ \\
\hline & 1 child & $25(8 \%)$ \\
\hline & 2 children & $55(18 \%)$ \\
\hline & 3 or more children & $10(3 \%)$ \\
\hline \multirow[t]{4}{*}{ Number of cars in the household } & None & $83(28 \%)$ \\
\hline & 1 car & $152(51 \%)$ \\
\hline & 2 cars & $60(20 \%)$ \\
\hline & 3 cars or more & $4(1 \%)$ \\
\hline \multirow[t]{5}{*}{ Mode } & Bicycle & $147(49 \%)$ \\
\hline & Bicycle + Transit & $55(18 \%)$ \\
\hline & Transit & $25(8 \%)$ \\
\hline & Park \& ride & $17(6 \%)$ \\
\hline & Car & $55(18 \%)$ \\
\hline \multirow{5}{*}{$\begin{array}{l}\text { I use apps because the help me select the best (Please note: } \\
\text { multiple responses possible) }\end{array}$} & mode of transport for a given trip & $29(10 \%)$ \\
\hline & time to make a given trip & $82(27 \%)$ \\
\hline & route for a given trip & $78(26 \%)$ \\
\hline & $\begin{array}{l}\text { They do not help me with travel } \\
\text { planning }\end{array}$ & $16(5 \%)$ \\
\hline & $\begin{array}{l}\text { N/A, I generally do not use mobile } \\
\text { travel applications }\end{array}$ & $156(52 \%)$ \\
\hline
\end{tabular}

work, and $25 \%$ of the total sample reported using transit related applications. Finally, the survey asked participants to state their agreement and the level of importance on a scale of one to five with various statements which are presented in Table 2 .

\section{Methodological Approach}

As the primary goal of this study is to understand the reasons affecting modal choices and how the use of ICTs and personal opinions and attitudes influence the decision- 


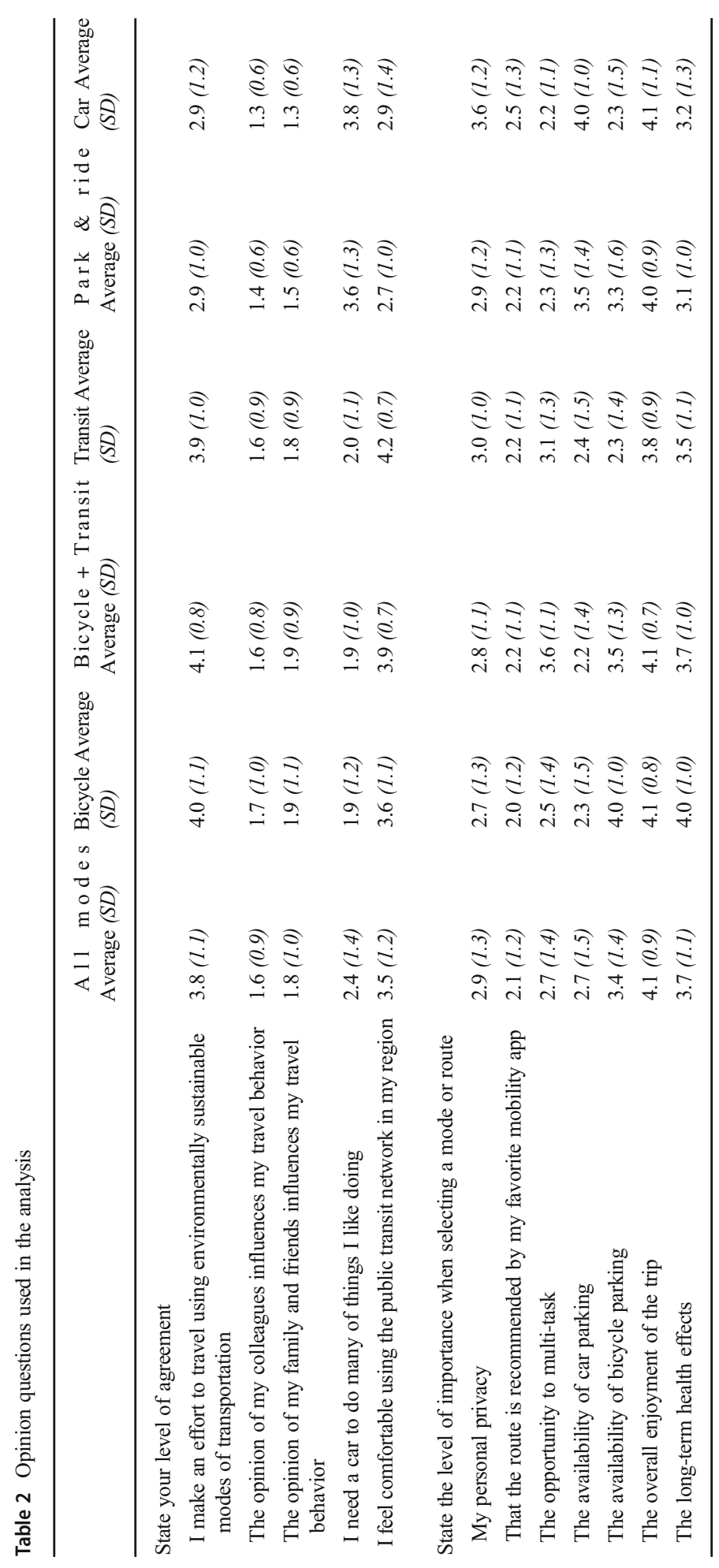


making process, the analysis is conducted using hybrid choice models with latent variables (also known as an integrated choice and latent variable model) accounting for attitudinal traits (McFadden 1986; Ben-Akiva et al. 2002). The main reason for making use of this approach is that, while it does not necessarily offer a better predictive capability (Vij and Walker 2016), it allows to establish how unobservable constructs (e.g. attitudinal or perceptual latent variables) explain both the model choices as well as attitudinal indicators collected on a Likert scale. This approach also makes it possible to consider to which extent the preference for a given alternative can be attributed to unobservable traits. In this study, we focus on attitudinal traits (i.e. individual specific latent constructs), which depend exclusively on the characteristics of the individuals and not to exogenous characteristics of the alternatives (BahamondeBirke et al. 2017), such as the importance that individuals set upon different services or how they interact with their social environment (see Table 2).

Modal choices are usually evaluated on the basis of discrete choice models (Train 2009; Ortuzar and Willumsen 2011) which, in turn, customarily rely on random utility theory (Thurstone 1927; McFadden 1974). Under these assumptions, it is postulated that when confronted with a choice-set $A_{q}$, consisting of different alternatives $i$, individuals $q$ will opt for the alternative that maximizes their expected utility $U_{i q}$. Then, it is assumed that $q$ will choose $i$, if and only if:

$$
U_{i q}>U_{j q} \forall j \neq i
$$

Consequently, the probability with which a given individual will opt for $i$ is equal to the probability that eq. [1] holds. The utility $U_{i q}$, in turn, can be expressed as the sum of a representative utility $V_{i q}$ (accounting for all variables the analyst controls for) and error component $\varepsilon_{i q}$ representing all factors affecting the decision that are ignored by the analyst so that:

$$
\begin{aligned}
& U_{i q}=V_{i q}+\varepsilon_{i q} \\
& V_{i q}=\beta_{x i} \cdot X_{i q}
\end{aligned}
$$

where $X_{i q}$, is a vector of observed attributes of the alternative $i$, and observed characteristics of the individual $q$, and $\beta_{x i}$ are vectors of parameters to be estimated. $\varepsilon_{i q}$ can follow any desired distribution. Assuming i.i.d. EV1 error terms leads to well-known MultiNomial Logit model (MNL), which has the particularity of leading to closed-form probability function (Domencich and McFadden 1975). While the latter assumptions are fairly restrictive, they can be relaxed without giving up the convenient MNL probabilities, by adding $m$ error terms $\nu_{m i q}$ (to be considered via simulation) representing any desired distribution. This specification leads to the Mixed Logit model (ML) (Cardell and Dunbar 1980), and it can be expressed e.g. in the following fashion:

$$
U_{i q}=V_{i q}+\sum_{m} \nu_{m i q}+\varepsilon_{i q}
$$

where if we assume $\nu_{\text {miq }}$ do not simply represent a given unobservable distribution (to be inferred on the basis of the choices), but underlying latent constructs accounting for 
unobserved attitudes affecting both the observed choices as well as the stated indicators $I_{k q}$, we can assume that:

$$
I_{k q}=\sum_{m} \gamma_{m k} \cdot \eta_{m q}+v_{k q} \quad \nu_{m i q}=\beta_{m i} \cdot \eta_{m q}
$$

In eq. [4], $\gamma_{m k}$ and $\beta_{m i}$ are parameters to be estimated, while $v_{k q}$ represents an error term. As the indicators $I_{k q}$ are stated on a Likert scale, it is expedient to model them as ordinal outcomes by assuming that $v_{k q}$ follows a standard Logistic distribution, which leads to Ordinal Logit (OL) probabilities.

When framing the model in this fashion, $\eta_{m q}$ represents an individual specific latent construct (latent variable - LV), which explains both the choices and the indicators; hence, (depending on the indicator being explained), it can be interpreted as an underlying attitudinal trait affecting both kinds of observations and correlating attitudinal indicators and modal choices. It is important to note that, as previously mentioned, $\eta_{q}$ is not a deterministic value but a distribution, which is consistent with our assumptions, as the modeler cannot positively observe an underlying trait (like an attitude), but only establish a probability of an individual $q$ being associated with a given value for the LV $\eta_{m q}$. Consequentially, $\eta_{m q}$ is usually modeled via structural equations as:

$$
\eta_{m q}=\alpha_{m y} \cdot Y_{q}+\varsigma_{m q}
$$

Where $Y_{q}$ represents a vector characteristics of the individuals (which may or may not overlap with $X_{i q}$ ), while $\alpha_{m y}$ is a vector of parameters to be estimated and $\varsigma_{k q}$ represents an error term giving rise to the distribution of $\eta_{m q}$. The parameters estimated for the structural equation (eq. [5]) $\alpha_{m y}$ imply that depending on their observed characteristics, individuals $q$ are likely to exhibit different attitudinal traits. Because of identifiability issues, it is customary to normalize w.l.o.g. both the expected value as well as the standard deviation of $\varsigma_{\mathrm{kq}}$.

The former assumptions lead to the following integrated likelihood function, in which the first element represents the likelihood of the chosen alternative being selected (with $y$ taking and integer value if the alternative is selected and zero otherwise) and the second element stands for the likelihood of observing a given set of indicators. Finally, the third element represents the mixing distribution:

$$
L=\int_{\eta} P(y \mid X, \eta ; \beta, \varepsilon) \cdot P(I \mid \eta ; \gamma, v) \cdot f(\eta \mid X, Y ; \alpha, \varsigma) \cdot d \varsigma
$$

As previously mentioned, if the elements of $\varepsilon$ are assumed to follow an EV1 distribution, the first element of [6] is given by an MNL probability-kernel. Different

\footnotetext{
${ }^{1}$ Under the assumption that the distribution considered to represent $\varsigma_{k q}$ can be characterized using two parameters (e.g. Normal, Logistic, or Uniform distributions, among many others).
} 
representations can be used to describe the probability functions associated with the second element, but it is customary to either assume a continuous representation of the probabilities (Ben-Akiva et al. 2002) or to rely upon an ordered logit (OL) probability kernel (Daly et al. 2012; Bahamonde-Birke and Ortúzar 2017).

As the integral depicted in eq. [6] cannot be reduced to a closed-form expression, it is customary to solve it relying on numerical techniques, such as maximum simulated likelihood estimation (Bhat 2001), in which the integral is replaced by the average of a large number of simulated draws depicting the distribution over which the variables ought to be integrated.

\section{Results}

Besides the objective of better understanding the relationship between mode choice and the use of ICTs, another related goal of this study is to identify how different groups of people, characterized in terms of their attitudinal traits, approach modal choices. This allows for understanding the importance of ICT-use in modal choices relative to the importance of the intrinsic characteristics of the individuals. For this purpose, it is necessary to identify potential attitudinal traits affecting modal choices and to consider an appropriate form to capture them making use of the available information. Therefore, latent factor analysis and structural equation modeling are conducted to identify attitudinal traits and to consider how different individuals (characterized in terms of their socio-economic information) relate to these attitudinal traits.

As a first modeling step, factor analysis is employed to understand how the collected indicators relate to each other, and in order to validate the hypothesis on how underlying attitudinal traits are being captured by the indicators. First, Principal Component Analysis was employed using SPSS software to understand how the survey questions relating to mobility needs and expectations relate to each other. This statistical method captures variability in the data and creates factor groupings by considering the total number of included survey questions. Questions related to transport attitudes and the use of mobile applications for travel, and that are asked using Likert-scale to measure agreement $(1=$ strongly disagree, $5=$ strongly agree $)$, were included in this phase of the analysis (Table 2). To maximize the variance of the squared loadings, Varimax rotation was used with Eigen values greater than one. This allows to confirm our hypothesis and to identify four latent variables describing traveller types or segments. The results of the factor analysis can be found in Appendix I. We constrain the analysis to include only loadings that are greater or less than .3 or -.3 respectively.

The results allow us to differentiate four clusters of indicators, for which we assume the existence of four different underlying latent variables, namely "car-oriented people", "bicycle-oriented people", "influenced by others", and "transit-oriented people". These latent variables were related to the aforementioned clusters on the basis of the results of the factor analysis, but also taking theoretical consideration into account. This is why the item concerning an individual's comfort using public transit is associated with the latent variable "transit-oriented" only, and not with "car-oriented" despite the results of the load factors. The results indicate that the latent variable "car-oriented people" groups together individuals who place privacy as greatly important, who state they need a car, value the importance of car parking, and are not focused on prioritizing 
environmentally friendly modes of transport. "Bicycle oriented" individuals place a great deal of importance on the availability of bicycle parking, the health benefits of travel, and select their mode based on the overall enjoyment of the trip. Latent variable three is composed of individuals whose mode choice in largely influenced by the opinions of their families, friends, and colleagues. Finally, "transit-oriented" individuals are characterized by the fact that they feel comfortable using public transit, their value of multi-tasking, and the usage of mobile applications that help them select the best route.

In a second step, using SPSS AMOS, we consider how the individuals' sociodemographic information relates to the previously identified latent constructs (at this stage, it was assumed that the collected indicators were a continuous expression of the underlying latent variables). This information is used to facilitate the specification of the utility functions and of the structural equations of the hybrid choice model.

\subsection{Modeling Mode Choices}

The main aim of this work is to consider how mode choices relate to the use of ICTs, in this case mobile applications, individuals' personal characteristics and attitudes. Consequentially, a discrete choice model on modal choices is estimated to assess the relationship between mode selection, attitudes, and the usage of mobile applications. The model considers five transportation alternatives, namely: bicycle, transit, car, bicycle and transit, and park and ride (car and transit) and as the focus is set upon the individuals (in terms of their use of ICT and attitudinal traits), no characteristics of the alternatives are considered.

In line with the methodological framework described in Section 3, hybrid discrete choice models were estimated. The information arising from the analysis described in Section 4 was used in the specification of the models; however, the models were estimated by maximizing the likelihood of observing the stated indicators as well as the modal choices simultaneously. Modal choices were considered relying on a mixed MNL probability-kernel, while for the indicators mixed OL-probability kernel were used. The error terms of the LV (eq. [5]) were assumed to be normally distributed, and their variance was normalized to $1 \mathrm{w} .1$. o.g. To compute the simulated choice probabilities, 1000 Modified Latin Hypercube Sampling (Hess et al. 2006) were considered. Alternatives involving cars (car, and park and ride) were considered to be available if the individual both reported having a driver's license and had a car available in the household, while alternatives involving bicycles (bicycle, and bicycle and transit) were considered to be available if the number of adults' bicycles in the household was greater than one. Because of numerical issues, the first two levels of the indicator "Importance of car parking" were considered as a single category ${ }^{2}$; consequentially the measurement equation associated with this indicator had only four possible outcomes (opposite to five for the remaining indicators). Biogeme (Bierlaire 2020) was used to perform the estimations.

\footnotetext{
${ }^{2}$ Independent tests showed that no statistically significant difference existed between the first two thresholds of the measurement equations associated with the indicator. Consequentially, this measure should not have any impact on the explanatory capability of the model.
} 
Figure 1 presents a diagrammatic representation of the best model being estimated and Table 3 reports the results of the structural equations and of the mode choice model (considering cycling - bicycle - as the reference category). The results of the measurement equations (equations relating the LV with the indicators) are presented in Appendix II. We relied upon the likelihood ratio test to select the hybrid model presented below. In addition, to assess model fit, we used the final log likelihood of the hybrid model (-3543.33), the choice model (-212.69), and indicators' measurement model (-3330.64-9 indicators).

One-tailed statistical tests are used when there is an evident notion on the direction of the effect of a given explanatory variable, in accordance with modeling hypothesis (e.g. it is assumed that the number of cars in the household must have a non-negative impact on the proclivity of car-oriented people). Otherwise, two-tailed test are used.

The table shows that several socio-demographic factors influence the latent factors representing individuals who are considered to be car-oriented (LV1 car-oriented), bicycle-oriented (LV bicycle-oriented), and influenced by the travel behavior of others (LV influenced). LV transit-oriented, was not found to have any statistically significant impact on mode choice, likely due to the fact there is limited variability in the population. This variable is therefore not included in the final model. The latent variable representing being car-oriented is influenced by the number of cars, children, and people in the household. Households with lower numbers of adults are more likely to be caroriented. In addition, as the number of people and cars increase in a household, so does the likeliness that individuals in the household will be car-oriented. The latent variable that represents being bicycle-oriented is influenced by an individual's age and the number of cars and children in the household. Individuals who live in households with more children are more likely to be bicycle-oriented, and individuals who are middle aged and live in households with fewer cars tend to be less car-oriented. The relationship between the increasing number of children and being bicycle-oriented may be due to the fact that households with children tend to use bicycles more often in the Netherlands since schools promote the use of bicycles for transport purposes (Pucher and Dijkstra

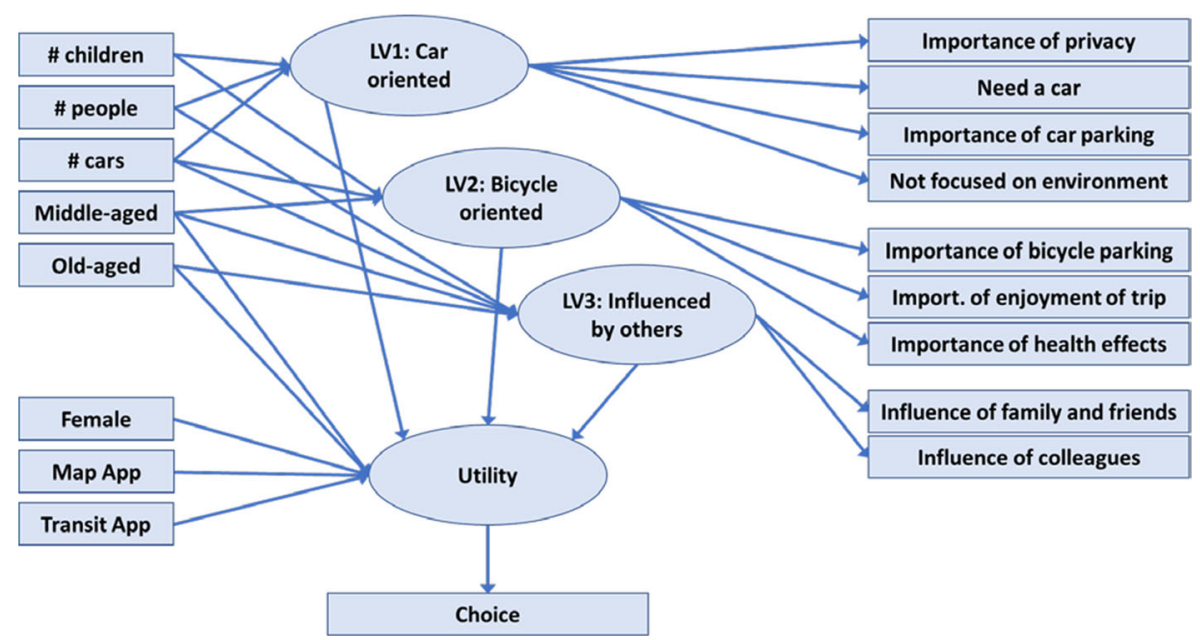

Fig. 1 Diagrammatic representation of the selected model 
Table 3 Model Results

\begin{tabular}{|c|c|c|c|c|}
\hline Variable & Equation & Estimate & Standard Deviation & $t$-test \\
\hline Number of cars & S.E. LV Car oriented & 1.18 & $(0.119)$ & $9.91 *$ \\
\hline Number of people & S.E. LV Car oriented & -0.411 & $(0.126)$ & $-3.26 * *$ \\
\hline Number of children & S.E. LV Car oriented & 0.365 & $(0.152)$ & $2.4 * *$ \\
\hline Middle-aged & S.E. LV Bicycle oriented & -1.31 & $(0.235)$ & $-5.59 * *$ \\
\hline Number of cars & S.E. LV Bicycle oriented & -0.299 & $(0.148)$ & $-2.02 * *$ \\
\hline Number of children & S.E. LV Bicycle oriented & 0.364 & $(0.137)$ & $2.65 * *$ \\
\hline Middle-aged & S.E. LV Influenced & -0.847 & $(0.343)$ & $-2.47 * *$ \\
\hline Old-aged & S.E. LV Influenced & -1.3 & $(0.362)$ & $-3.59 * *$ \\
\hline Number of cars & S.E. LV Influenced & -0.901 & $(0.209)$ & $-4.31 * *$ \\
\hline Number of people & S.E. LV Influenced & 0.392 & $(0.127)$ & $3.08 * *$ \\
\hline$\overline{A S C}$ Bicycle & Utility Bicycle & $\mathbf{0}$ & (fixed) & - \\
\hline ASC Transit & Utility Transit & -6.92 & $(0.985)$ & $-7.03 * *$ \\
\hline Female & Utility Transit & 3.19 & $(0.847)$ & $3.76 * *$ \\
\hline Transit app user & Utility Transit & 7.11 & $(0.855)$ & $8.31 *$ \\
\hline Transit app user $*$ Middle-aged & Utility Transit & -1.81 & $(0.948)$ & $-1.91 *$ \\
\hline LV Bicycle oriented & Utility Transit & -1.08 & $(0.462)$ & $-2.34 *$ \\
\hline ASC Car & Utility Car & -4.58 & (1.09) & $-4.22 * *$ \\
\hline Female & Utility Car & -1.47 & $(0.607)$ & $-2.42 * *$ \\
\hline Map app user & Utility Car & 4.81 & $(0.957)$ & $5.02 *$ \\
\hline$L V$ Car oriented & Utility Car & 2.1 & $(0.504)$ & $4.16^{*}$ \\
\hline LV Bicycle oriented & Utility Car & -1.27 & $(0.372)$ & $-3.41 *$ \\
\hline LV Influenced & Utility Car & -0.648 & $(0.356)$ & $-1.82 *$ \\
\hline ASC Bike+Transit & Utility Bike + Transit & -2.78 & $(0.344)$ & $-8.08 * *$ \\
\hline Transit app user & Utility Bike + Transit & 6.47 & $(0.904)$ & $7.15 *$ \\
\hline Transit app user * Middle/Old-aged & Utility Bike + Transit & -1.38 & $(0.787)$ & $-1.75 * *$ \\
\hline ASC Park \& Ride & Utility Park \& Ride & -4.53 & $(1.07)$ & $-4.23 * *$ \\
\hline Map app user & Utility Park \& Ride & 4.2 & $(0.943)$ & $4.46^{*}$ \\
\hline Map app user * Middle/Old-aged & Utility Park \& Ride & -1.87 & $(1.08)$ & $-1.72 * *$ \\
\hline Transit app user & Utility Park \& Ride & 1.68 & $(0.866)$ & $1.94 *$ \\
\hline Transit app user $*$ Old-aged & Utility Park \& Ride & -4.22 & $(0.958)$ & $-4.41 * *$ \\
\hline$L V$ Car oriented & Utility Park \& Ride & 1.33 & $(0.469)$ & $2.84 *$ \\
\hline LV Bicycle oriented & Utility Park \& Ride & -0.666 & $(0.45)$ & $-1.48 *$ \\
\hline$\underline{L}$ Influenced & Utility Park \& Ride & -0.637 & $(0.385)$ & $-1.65 *$ \\
\hline Number of observations & & & 299 & \\
\hline Number of parameters & & \multicolumn{3}{|c|}{$10(\mathrm{SE})+22(\mathrm{DC})+36(\mathrm{ME})$} \\
\hline Log-likelihood DC component & & \multicolumn{3}{|c|}{-212.69} \\
\hline Log-likelihood measurement model & & \multicolumn{3}{|c|}{-3330.64} \\
\hline Log-likelihood overall model & & \multicolumn{3}{|c|}{-3543.33} \\
\hline
\end{tabular}

*one-tailed test; ** two-tailed test 
2003). Finally, people who are older or middle aged are less susceptible to other people's opinions than younger people, and individuals who live in households with more people are more susceptible to other people's opinions.

The results of the mode choice model reveal that there is a clear relationship between ICT use and mode choice, and while not unexpected, does reveal mobile application use is often mode-specific. For example, an unsurprising finding is that individuals who use a mobile transit app are more likely to commute using transit or another combined mode involving transit (bike + transit or park \& ride) than commuting by car or bike. Along these lines, the effect of ICT usage is similar on transit and on bike + transit (which implies a similar usage on both alternatives), while being stronger than on park $\&$ ride. Also, the effect is found to be substantially stronger for younger than for older individuals, implying that being an app user has a much greater impact on the former. Even, in the case of older individuals, being a transit app user has no positive impact on the propensity of communing using park \& ride.

Similarly, we found a strong correlation between the use of map-related mobile applications and mode choices involving car (car, and park \& ride). However, the correlation among using a map app is stronger for car commuters than for users of park $\&$ ride facilities. As in the previous case, ICT use has a stronger effect on younger individuals (although in the case of car only, no differences by age group could be identified).

It is important to note that in the case of park \& ride the effects of being either a transit or app map user were independently weaker than on other alternatives. Nonetheless, both effects are additive, reflecting the multimodal nature of the alternative, which profit from both navigation and transit apps.

Furthermore, the findings reveal that females are more likely to use transit and less likely to travel by car for commuting than males. However, no gender related effects were identified in association with the use of apps and mode choice. Furthermore, and unsurprisingly, bicycle-oriented people associate motorized transportation (transit, car, and par and ride) with a negative utility when contrasted with the reference alternative (bicycle); this disutility is similar across alternatives and it does not extend to the mixed mode involving a bicycle (bike and transit). Similarly, car-oriented individuals tend to prefer cars over other alternatives, while it is also possible to identify a positive utility associated with park and ride (also the effect is weaker than in the case of unimodal cars). Finally, individuals who are influenced by their friends, family, and colleagues, are less likely to travel by car or to use park \& ride facilities, which is consistent with the expectations, as these forms of transportation are usually considered as lessdesirable from a societal and individual-health viewpoint (De Groot et al. 2008; Mueller et al. 2015).

\section{Discussion}

This study assesses the relationship between mode choice, travel attitudes, the use of mobile mobility applications and personal characteristics among staff and faculty members at a large employment hub in Utrecht, the Netherlands. The results of the person-based mode-choice model demonstrate that strong correlations exist between the kinds of mobile applications individuals use, their attitudes towards travel and their 
transportation mode. This means that there is a strong correlation between the kinds of mobile applications that an individual uses and the mode they use. While in some cases these findings are unsurprising, this is not always the case. For example, map-based mobile applications could be used by all mode users but are strongly associated with car drivers. Transit applications are used by all modes that include transit usage including combinations with driving and cycling. The effect of using transit applications is similar for transit only and for bike and transit while being required to be used in combination with a navigation app to achieve a similar effect in the case of park \& ride. Finally, it is important to note that no mobile application seems to favor the use of active modes. A possible explanation for the phenomenon is that active modes are less dependent on the conjuncture and, consequentially, benefit less from real-time information. Given the latter, it is debatable whether the use and promotion of ICT technologies can favor active transportation for commuting.

The results also show that the use of mobile applications by young individuals exhibit a stronger correlation with their mobility behavior than in the case of middleaged and older users. These results quantitatively add to the qualitative results by van Lierop et al. (2020) who found that younger cyclists relied more heavily on mobile mapping applications compared to older ones. No significant differences regarding ICT use and modal choices were found in association with gender. This finding also suggests that because certain mode users use mobile travel applications more than others, ICT based nudging policies will only be effective for certain individuals, while social incentives may be more successful for others. The model results clearly demonstrate that in order to motivate an entire population to increase their use of sustainable modes a multi-faceted strategy is necessary as different populations segments are more or less likely to be influenced by ICT and social incentives. The choice model results suggest that individuals who are influenced by their friends, family, and colleagues, are less likely to travel by car or to use park \& ride facilities. These findings are related to those presented by Alfonzo (2005) who applied a social-ecological model to understand individuals' decisions to walk for transportation. Other authors have also suggested that mode selection is influenced by social context (Willis et al. 2015), and policies that are developed based on the social understanding of mode choice are more likely to be effective. Therefore, in the case of commuting to the UU Science Park, social incentives by colleagues and friends may be effective to stimulate continued use of active modes, but is unlikely to be effective in motivating drivers and park $\&$ rides users to shift to using sustainable modes. For this group, motivations related to financial incentives or work location may be more effective. This is especially true for older commuters who, compared to younger commuters, are less likely to be influenced by others.

Finally, the results of the analysis demonstrate that currently commuters who do use mobile travel applications related to travel tend to use them to determine their route choice and travel time. While this study focuses on travel attitudes, a major limitation is that level-of-service variables such as overall travel times, mode availability, and travel costs are not included. Future studies should test the impact of the latent constructs while controlling for such level-of-service variables as well as land use variables. Further research is also needed to better understand how mobile applications can be used to better assess and understand how sustainable mode usage can be nudged using mobile applications. In the future, studies should also set out to better understand what 
influences individuals to select modes which are not only sustainable, but also shared and collective. Further research in this area is needed to provide insight into how regions can motivate the adoption of sustainable and collective modes of transportation both today and in the future. Moreover, in the future, cities will need to consider multimodal transportation as a sustainability goal since regions with mode shares distributed between personalized automated vehicles, shared automated vehicles, rail, cycling, walking, as well as other modes are not only likely to see reductions in vehicle miles travelled and congestion, but also to experience increases in the overall health of populations. While the results of this study demonstrate that multi-modal travel is already an attractive option for many, the results of the analysis suggest that users who make multi-modal trips such as park \& ride currently use one mobile application per mode, revealing a potential need for integrated mobility applications. Since communications technologies are becoming increasingly key to connecting people with their preferred modes, it is fundamental to understand the factors that influence individuals to remain loyal to sustainable transportation when other modes are available for the same trip both today, and in the future.

\section{Appendix}

Table 4 Factor analysis

\begin{tabular}{|c|c|c|c|c|}
\hline & $\begin{array}{l}\text { Car } \\
\text { oriented }\end{array}$ & $\begin{array}{l}\text { Bicycle } \\
\text { oriented }\end{array}$ & $\begin{array}{l}\text { Influenced } \\
\text { by others }\end{array}$ & $\begin{array}{l}\text { Transit } \\
\text { oriented }\end{array}$ \\
\hline Importance of privacy &, 565 &, 425 & & \\
\hline Need a car & 674 & & & \\
\hline Importance of parking &, 784 & & & \\
\hline Focused on the environment &,- 709 & & & \\
\hline Importance of bicycle parking & &, 685 & & \\
\hline Importance of the enjoyment of the trip & &, 757 & & \\
\hline Importance of the health effects & &, 732 & & \\
\hline Influence of family and friends & & & ,906 & \\
\hline Influence of colleagues & & & ,915 & \\
\hline Feel comfortable using public transit &,- 594 & & &, 441 \\
\hline Importance of multi-tasking & & & &, 787 \\
\hline Select route based on app & 351 & & & 630 \\
\hline
\end{tabular}

Extraction Method: Principal Component Analysis

Rotation Method: Varimax with Kaiser Normalization

Variance: $62.6 \%$ 
Table 5 Measurement Equations

\begin{tabular}{|c|c|c|}
\hline Variables & Value & St. Dev \\
\hline Indicator Importance of privacy; Threshold 1 & -1.67 & 0.257 \\
\hline Indicator Importance of privacy; Threshold 2 & -0.273 & 0.243 \\
\hline Indicator Importance of privacy; Threshold 3 & 1.09 & 0.249 \\
\hline Indicator Importance of privacy; Threshold 4 & 2.9 & 0.309 \\
\hline Indicator Need a car; Threshold 1 & -0.494 & 0.244 \\
\hline Indicator Need a car; Threshold 2 & 1.03 & 0.236 \\
\hline Indicator Need a car; Threshold 3 & 1.81 & 0.251 \\
\hline Indicator Need a car; Threshold 4 & 3.01 & 0.274 \\
\hline Indicator Importance of car parking; Threshold 1 & 0.141 & 0.254 \\
\hline Indicator Importance of car parking; Threshold 2 & 0.916 & 0.254 \\
\hline Indicator Importance of car parking; Threshold 3 & 2.56 & 0.276 \\
\hline Indicator Not focused on environment; Threshold 1 & -3.89 & 0.339 \\
\hline Indicator Not focused on environment; Threshold 2 & -2.66 & 0.274 \\
\hline Indicator Not focused on environment; Threshold 3 & -1.11 & 0.245 \\
\hline Indicator Not focused on environment; Threshold 4 & 0.824 & 0.248 \\
\hline Indicator Importance of bicycle parking; Threshold 1 & -2.59 & 0.218 \\
\hline Indicator Importance of bicycle parking; Threshold 2 & -1.81 & 0.202 \\
\hline Indicator Importance of bicycle parking; Threshold 3 & -0.867 & 0.192 \\
\hline Indicator Importance of bicycle parking; Threshold 4 & 0.628 & 0.194 \\
\hline Indicator Importance of enjoyment of trip; Threshold 1 & -5.53 & 0.531 \\
\hline Indicator Importance of enjoyment of trip; Threshold 2 & -4.12 & 0.295 \\
\hline Indicator Importance of enjoyment of trip; Threshold 3 & -2.13 & 0.207 \\
\hline Indicator Importance of enjoyment of trip; Threshold 4 & 0.253 & 0.193 \\
\hline Indicator Importance of health effects; Threshold 1 & -4.37 & 0.345 \\
\hline Indicator Importance of health effects; Threshold 2 & -2.72 & 0.226 \\
\hline Indicator Importance of health effects; Threshold 3 & -1.13 & 0.195 \\
\hline Indicator Importance of health effects; Threshold 4 & 0.689 & 0.197 \\
\hline Indicator Influence of family and friends; Threshold 1 & -0.608 & 0.317 \\
\hline Indicator Influence of family and friends; Threshold 2 & 1.28 & 0.327 \\
\hline Indicator Influence of family and friends; Threshold 3 & 2.96 & 0.377 \\
\hline Indicator Influence of family and friends; Threshold 4 & 4.72 & 0.583 \\
\hline Indicator Influence of colleagues; Threshold 1 & -0.0105 & 0.32 \\
\hline Indicator Influence of colleagues; Threshold 2 & 2.03 & 0.344 \\
\hline Indicator Influence of colleagues; Threshold 3 & 3.31 & 0.394 \\
\hline Indicator Influence of colleagues; Threshold 4 & 4.73 & 0.57 \\
\hline
\end{tabular}

t-tests agains zero not relevant, given the nature of ordered model and thersholds

Acknowledgements The authors would like to thank the participants of the Chan Wui \& Yunyin Rising Star Workshop for their invaluable feedback on the paper as well as the anonymous reviewers. We would also like the thank the Utrecht University Green Office and the participants of the study for their contribution. 
Open Access This article is licensed under a Creative Commons Attribution 4.0 International License, which permits use, sharing, adaptation, distribution and reproduction in any medium or format, as long as you give appropriate credit to the original author(s) and the source, provide a link to the Creative Commons licence, and indicate if changes were made. The images or other third party material in this article are included in the article's Creative Commons licence, unless indicated otherwise in a credit line to the material. If material is not included in the article's Creative Commons licence and your intended use is not permitted by statutory regulation or exceeds the permitted use, you will need to obtain permission directly from the copyright holder. To view a copy of this licence, visit http://creativecommons.org/licenses/by/4.0/.

\section{References}

Alfonzo MA (2005) To walk or not to walk? The hierarchy of walking needs. Environ Behav 37(6):808-836 AlleCijfers.nl (2019). "Informatie gemeente Utrecht." Retrieved 1 October 2019, 2019, from https://allecijfers. $\mathrm{nl} /$ gemeente/utrecht/

Bahamonde-Birke FJ, de Dios Ortúzar J (2017) Analyzing the continuity of attitudinal and perceptual indicators in hybrid choice models. Journal of Choice Modelling 25:28-39

Bahamonde-Birke FJ, Kunert U, Link H, Ortúzar JD (2017) About attitudes and perceptions: finding the proper way to consider latent variables in discrete choice models. Transportation 44(3):475-493

Ben-Akiva $\mathrm{M}$ et al (2002) Integration of choice and latent variable models. Perpetual motion: Travel behaviour research opportunities and application challenges:431-470

Bhat CR (2001) Quasi-random maximum simulated likelihood estimation of the mixed multinomial logit model. Transp Res B Methodol 35(7):677-693

Bierlaire M (2020) A short introduction to PandasBiogeme, Technical report TRANSP-OR 200605. E. Transport and Mobility Laboratory, EPFL

Bohte W, Maat K, van Wee B (2009) Measuring attitudes in research on residential self-selection and travel behaviour: a review of theories and empirical research. Transp Rev 29(3):325-357

Button, K. (2010). Transport economics, Edward Elgar Publishing

Cardell N, Dunbar F (1980) Measuring the societal impacts of automobile downsizing. Transportation Research Part A: General 14(5-6):423-434

Cervero R, et al. (2002) "Transit-oriented development and joint development in the United States: a literature review." TCRP research results digest(52)

Chou P, et al. (2014) "Effects of service quality and customer satisfaction on customer loyalty in high-speed rail services in Taiwan

Daly A, Hess S, Patruni B, Potoglou D, Rohr C (2012) Using ordered attitudinal indicators in a latent variable choice model: a study of the impact of security on rail travel behaviour. Transp 39(2):267-297

De Groot J et al (2008) Transportation trends from a moral perspective: value orientations, norms and reducing car use. New transportation research progress:67-91

Domencich T and McFadden D (1975). Urban travel demand - a behavioral analysis. Amsterdam, the Netherlands

Gountas J, Gountas S (2007) Personality orientations, emotional states, customer satisfaction, and intention to repurchase. J Bus Res 60(1):72-75

Hess S, Train KE, Polak JW (2006) On the use of a modified latin hypercube sampling (MLHS) method in the estimation of a mixed logit model for vehicle choice. Transp Res B Methodol 40(2):147-163

Jacobson S et al (2011) A note on the relationship between obesity and driving. Transp Policy 18(5):772-776

Lai W, Chen C (2011) Behavioral intentions of public transit passengers - the roles of service quality, perceived value, satisfaction and involvement. Transp Policy 18(2):318-325

Martin A, Suhrcke M, Ogilvie D (2012) Financial incentives to promote active travel: an evidence review and economic framework. Am J Prev Med 43(6):e45-e57

McFadden D (1974) Conditional logit analysis of qualitative choice behavior. Frontiers in econometrics. P. Zarembka. New York, Academic Press: 105-142

McFadden D (1986) The choice theory approach to market research. Mark Sci 5(4):275-297

Molander S, Fellesson M, Friman M, Skålén P (2012) Market orientation in public transport research - a review. Transp Rev 32(2):155-180

Mueller N, Rojas-Rueda D, Cole-Hunter T, de Nazelle A, Dons E, Gerike R, Götschi T, Int Panis L, Kahlmeier S, Nieuwenhuijsen M (2015) Health impact assessment of active transportation: a systematic review. Prev Med 76:103-114 
Nguyen-Phuoc DQ et al (2020) Factors influencing customer's loyalty towards ride-hailing taxi services-a case study of Vietnam. Transp Res A Policy Pract 134:96-112

Ogilvie D, Egan M, Hamilton V, Petticrew M (2004) Promoting walking and cycling as an alternative to using cars: systematic review. Bmj 329(7469):763

Olsson, L., et al. (2013). "Happiness and satisfaction with work commute." Soc Indic Res 111(1): 255-263

Ortuzar JD and Willumsen L (2011). Modelling transport, John wiley \& sons

Pucher J, Dijkstra L (2003) Promoting safe walking and cycling to improve public health: lessons from the Netherlands and Germany. Am J Public Health 93(9):1509-1516

Reddy S, Mun M, Burke J, Estrin D, Hansen M, Srivastava M (2010) Using mobile phones to determine transportation modes. ACM Transactions on Sensor Networks (TOSN) 6(2):1-27

Sallis J et al (2004) Active transportation and physical activity: opportunities for collaboration on transportation and public health research. Transp Res A Policy Pract 38(4):249-268

Sevtsuk A, Ratti C (2010) Does urban mobility have a daily routine? Learning from the aggregate data of mobile networks. J Urban Technol 17(1):41-60

Shaheen S, et al. (2020). Sharing strategies: Carsharing, shared micromobility (bikesharing and scooter sharing), transportation network companies, microtransit, and other innovative mobility modes. Transportation, Land Use, and Environmental Planning, Elsevier: 237-262

Şimşekoğlu Ö, Nordfjærn T, Rundmo T (2015) The role of attitudes, transport priorities, and car use habit for travel mode use and intentions to use public transportation in an urban Norwegian public. Transp Policy 42:113-120

St-Louis E, et al. (2014) "the happy commuter: a comparison of commuter satisfaction across modes." transportation research part F: traffic psychology and behaviour 26, part a(0): 160-170

Stumpel P, van Weperen S (2019) Monitor mobiliteitsplan. In: Utrecht, the Netherlands. Utrecht, Gemeente

Sunio V, Schmöcker J-D (2017) Can we promote sustainable travel behavior through mobile apps? Evaluation and review of evidence. Int J Sustain Transp 11(8):553-566

Thurstone L (1927) A law of comparative judgment. Psychol Rev 34(4):273-286

Train K (2009). Discrete choice methods with simulation, Cambridge university press

Transportation Research Board (1998) A handbook: using market segmentation to increase transit ridership. Washington, DC, Transportation Research Board: United States Federal Transit Administration

Turcotte M (2011). "commuting to work: results of the 2010 general social survey." Canadian social trends, statistics Canada catalogue no. 11-008-X

van Lierop D, Badami MG, el-Geneidy AM (2018) What influences satisfaction and loyalty in public transport? A critical review of the literature. Transp Rev 38(1):52-72

van Lierop D and El-Geneidy A (2016) "Enjoying loyalty: the relationship between service quality, customer satisfaction, and behavioral intentions in public transit." Res Transp Econ

van Lierop D, Soemers J, Hoeke L, Liu G, Chen Z, Ettema D, Kruijf J (2020) Wayfinding for cycle highways: assessing e-bike users' experiences with wayfinding along a cycle highway in the Netherlands. J Transp Geogr 88:102827

Vij A, Walker J (2016) How, when and why integrated choice and latent variable models are latently useful. Transp Res B Methodol 90:192-217

Wasfi R et al (2013) Achieving recommended daily physical activity levels through commuting by public transportation: unpacking individual and contextual influences. Health \& place 23:18-25

Willis DP, Manaugh K, el-Geneidy A (2015) Cycling under influence: summarizing the influence of perceptions, attitudes, habits, and social environments on cycling for transportation. Int J Sustain Transp 9(8):565-579

Publisher's note Springer Nature remains neutral with regard to jurisdictional claims in published maps and institutional affiliations.

\section{Affiliations}

\section{Dea van Lierop ${ }^{1} \cdot$ Francisco J. Bahamonde-Birke ${ }^{1}$}

Francisco J. Bahamonde-Birke

f.j.bahamondebirke@uu.nl; bahamondebirke@gmail.com 